\title{
Public policy and growth in Canada: An applied endogenous growth model with human and knowledge capital accumulation is
}

\author{
Ebru Voyvoda ${ }^{\mathrm{a}, *}$, Erinç Yeldan ${ }^{\mathrm{b}}$ \\ a Middle East Technical University, Department of Economics, 06800 Ankara, Turkey \\ b Ihsan Doğramac Bilkent University, Department of Economics, 06800 Ankara, Turkey
}

\section{A R T I C L E I N F O}

\section{Article history:}

Accepted 28 June 2015

Available online 30 July 2015

\section{Keywords:}

Endogenous growth

Education

R\&D

General equilibrium

Subsidization

Canadian economy

\begin{abstract}
A B S T R A C T
Evidence suggests that the Canadian economy is over-shadowed with lagging productivity growth and that its innovation strategy lacks a market-oriented focus; and is unbalanced and biased. We study this problem with the aid of a dynamic general equilibrium model driven by analytics of endogenous growth and investigate the viable policy options and assess the interactions between knowledge driven growth, acquisition of human capital, and the role of strategic public policy for the Canadian economy. We study alternative public policies aimed at fostering the development of human capital (investment in education) and those at enhancing investments in innovation. Based on the re-allocation effects triggered by public subsidization policies on higher education versus industry/business R\&D, our results corroborate that Canadian economy is falling short of its potential in (business) technological innovation. Our analyses further imply that the most welfare enhancing policy is to have a complementary mix of education and R\&D subsidization designed to avoid the trade-offs that emerge in the short run.
\end{abstract}

(c) 2015 Elsevier B.V. All rights reserved.

\section{Introduction}

In the face of accumulating evidence that Canada is lagging behind in productivity growth, there is a growing concern that its innovation strategy lacks market-oriented focus. It is argued that its aggregate national output remains lower than its potential, and that Canada is over-investing in education and under-investing in R\&D, business R\&D in particular. This asymmetry is highlighted in Cook (2008:1) who claimed, for instance, that "Canada's innovation strategy is unbalanced and biased; focused on technology-push, overlooking... market-led innovation". McFetridge (2008:2) in turn argues that "Canada's disappointing record is due, in part, to a lack of innovation in the business sector of the economy", and criticizes that this had been "a recurring theme... for more than forty years".

\footnotetext{
ฟ The research support by Human Resources and Skills Development Canada (9214-090002 ) is gratefully acknowledged. We are also grateful to three anonymous reviewers of this Journal, and to Nabil Annabi, Çă̆rı Sağlam, Madanmohan Ghosh and to participants of the seminars at Bilkent, Koç, Middle East Technical and Tuebingen Universities, Center for European Economic Research, and to the session participants at the 45th Annual Conference of the Canadian Economic Association for their most valuable suggestions and comments. Needless to further mentioning, all remaining errors and views expressed remain as solely our responsibility.

* Corresponding author. Tel.:+90 312 2102056; fax:+90 3122107964.

E-mail addresses: voyvoda@metu.edu.tr (E. Voyvoda),yeldane@bilkent.edu.tr (E. Yeldan).
}

Statistics Canada (2007) further reports that Canada's rate of growth of labor productivity has been lower than that of the United States over the last quarter of the last century, and that the gap seems to be widening. Sharpe (2007:21) has made an even stronger case arguing that "over 2000 to 2006, Canada's labor productivity growth in its manufacturing was only one-tenth of that witnessed in the US".

Conventional analysis suggests that the reason of this gap can be two-fold:

(1) diminishing returns to investments in physical capital, which is a well-known factor embedded in the traditional neoclassical paradigm; (2) slow rate of growth in technological innovation.

However, the Canadian reality signifies yet another mix: impediments to innovation; or rather, the widening gap between advances in pure sciences and commercialization of the fruits of this research within a balanced innovation system that is inclusive of a market-led, pullinnovation framework. Cook (2008:5) concludes for instance, that "Canada's innovation system has been disproportionately focused on fundamental research for nearly a century", and that, "recent innovation strategies have resulted in substantial increases in push-innovation funding; however, commercialization results have been disappointing and Canada is not considered an innovation leader". A natural issue of concern in bridging the aforementioned gap between the push and pull attributes of innovation is education and training of the research personnel, that is, the pace of human capital formation. This was highlighted in Expert 
Panel on Commercialization (2006) where, among many sets of recommendations, the Panel explicitly called for "new or expanded fellowship programs to employ undergraduate, graduate and postdoctoral students and recent graduates in the business sector"; and "a commercialization superfund to support research and training in university and nonproprietary laboratories in areas of research in which Canada could become a market leader."

Given these discussions, in this paper we ask what can be done to boost and manage Canada's productivity growth. Recent advances in the "new growth theory" identify and emphasize the roles of R\&D activities and accumulation of human capital as the key determinants in explaining disparity across countries in income per capita, productivity, and the rate of growth. Investment in education directly stimulates the productivity of the labor force, and thus provides significant externalities for growth. Similarly, R\&D activities conducted by both private and public sector raise the available knowledge stock and elicit capital accumulation. Thus, economic growth is fed from two sources which nourish each other: investments in education and R\&D capital accumulation.

The crucial roles attributed to R\&D activities and accumulation of human capital in explaining economic growth have led to construction of economic models which allow for sustained, boundless growth of per capita income, where long run performance depends on structural parameters and domestic and foreign fiscal policies. In this literature, a branch studied capital accumulation, which became a broader concept with the inclusion of human capital, as the engine of growth (Jones and Manuelli, 1990; King and Rebelo;, 1993; Rebelo, 1991). Another approach attributed a leading role to externalities in growth process. Each firm's physical (Arrow, 1962) and human (Lucas, 1988) capital investment unintendedly contributes to the productivity of other firms' capitals. Pioneered by Romer (1990), Grossman and Helpman (1991,1994), Aghion and Howitt (1997), a third approach focused on economic growth triggered by technological development and adoption of new technologies.

The new growth literature that followed the paths of the above mentioned literature, developed models that attempt to reconcile Romerian/ Krugmanesque R\&D-driven growth along with Lucasian human capital formation in which private industrial development, capital variety production, and technical skill dispersion lead to growth, given the importance of representation of knowledge-led economic conditions (Arnold, 1998; Dalgaard and Kreiner, 2001; Riberio-Thompson, 2000). Based on these hypotheses, models with joint consideration of human capital accumulation and endogenous technology contested the standard models of the literature where (steady-state) growth rate is only dependent on human capital variable(s) and their structural parameters, and showed that (steady-state) growth paths would also be affected by the level of innovative activities (Sequeira, 2008, 2011; Zeng, 2003).

Such contributions bring the issues of innovation, R\&D production, human capital formation and optimal design of public policies that take into account the simultaneous interaction among the mechanisms that contribute to the generation of economic growth to the forefront of analysis. Zeng (2003), utilizing a model with innovations, physical, and human capital, studies the impact of government policies on long-run growth and shows that long-run growth rate is responsive to the choice of government taxes and subsidies. Similarly, Hagedorn et al. (2003), in a model of endogenous growth with a combination of physical and human capital, and R\&D based technology accumulation calibrated to the US economy, investigate Ramsey-optimal taxation regimes and indicate that a government policy designed to lower the cost of financing for R\&D firms would help induce a higher level of private R\&D and a higher path of growth. Grossman (2007) in a two-period OLG model in which the young agent decides to devote time to increase (specialized) skill level or to remain unskilled, compares the growth implications of $\mathrm{R} \& \mathrm{D}$ subsidy to firms with a publicly provided education targeted to the development of (specialized) science and engineering skills. In a different setting, Agénor (2012) sets up an overlapping generations endogenous growth model with interactions between public capital, human capital and innovation, and emphasizes the trade-offs involved in the allocation of public spending to R\&D subsidies. Gomez and Sequeira (2014), in a recent paper present a model of R\&D, human capital, and physical capital with creative destruction. The model is calibrated to US economy and intertemporally budget-neutral policies are compared. The authors show that subsidies to R\&D are most welfare increasing when the main target is to keep the intertemporal budget balance.

Following these theoretical and empirical contributions, the main purpose of this study is to analytically investigate and assess the interactions between knowledge driven growth, acquisition of human capital, and the role of strategic public policy for the Canadian economy within the context of a general equilibrium, endogenous growth model. To this end, we investigate alternative public policies aimed at fostering the development of human capital (such as investments in education and learning) and those at enhancing total factor productivity through investments in innovation (such as subsidies to $\mathrm{R} \& \mathrm{D}$ ); and study the impact of various public policies on patterns of growth, along with their likely consequences from the points of view of per capita income growth, social welfare, burden to government budget and economic efficiency.

We calibrate the model to the real macroeconomic data of the "Canadian economy" and solve both for the transition and the steady-state path of the economic variables under an inter-temporal general equilibrium setting. With the aid of our analytical structure, we focus on the innovation/R\&D- and human capital-driven patterns of growth from a macroeconomic perspective. To this end, and briefly within the specifics of our model, we organize this study around the most conducive questions concerning public subsidization policy for enhancing growth and social welfare: promotion of human capital formation through subsidies to education expenditures or promotion of industry/business R\&D through (direct) subsidies to R\&D investment and the role of re-allocation effects on human capital triggered by such policies.

We also explicitly model the government accounts to be able to have a well-defined platform to compare the effects of alternative scenarios on the key variables of the macro economy. Calibrated to the Canadian macro data, the model associates and extends the frameworks of R\&D based endogenous growth models (Ghosh, 2007; Russo, 2004) and education based endogenous growth models (Annabi et al., 2011) in analyzing alternative policies to promote growth within the Canadian context. $^{1}$

Remaining pages of this paper are designed in five sections. In the second section, we present R\&D and human capital data, and provide a synopsis on the characteristics of the innovation-driven growth prospects for the Canadian economy. Analytical and algebraic set up of the model is presented in the third section, while policy analyses are conducted in section four. In the fifth section we summarize the main findings of the study and conclude. The data set and calibration strategy of the algebraic model are narrated in detail in a separate Appendix A.

\section{Growth with respect to $R \& D$ and human capital accumulation in the Canadian economy: facts and figures}

Concerns over promotion of R\&D and innovation-led growth are currently at the center stage of public policy debates in Canada. Based on the comparative OECD data, reports by Science, Technology and Innovation Council ${ }^{2}$ emphasize, for instance, that the Canadian economy has been in a "low ranking" position in terms of performance in R\&D in general; but especially reveals "low ranking" status in areas such as industry/business expenditure on $R \& D$, percentage of total $R \& D$

\footnotetext{
${ }^{1}$ Applied work analyzing alternative growth promoting policies either through R\&D or education based endogenous growth models within advanced country settings also include Diao et al (1999), Bye et al (2009) and Mattalia (2012).

2 State of the Nation (2008, 2010, 2012).
} 
performed by industry/business and industry/business investment in machinery and equipment (Table 1). On the other hand, Canada has been within the "high ranking" group in basic research performance, R\&D conducted by universities, and education level of its workforce (but with "low ranking" in the number of advanced degree graduates in the industry/business category).

Table 1 reveals that, according to the data compiled from OECD, Canada's Gross Expenditures on R\&D (GERD) to GDP ratio lied on average at $1.95 \%$ in 2003-2009 period. ${ }^{3}$ This ratio was higher than the EU-15 average, but fell behind that of the OECD. Yet, the GERD/GDP ratio for Canada has been decreasing since then from a level of $1.99 \%$ in 2003 , $1.92 \%$ in 2009 , and $1.62 \%$ in 2013 . In contrast, the GERD/GDP ratio for the EU-15 has been increasing steadily to reach to $2.00 \%$ in 2009 and $2.07 \%$ in 2013 . These outcomes were realized despite the clear intentions and a targeted focus that was laid in the Innovation Strategy document that was laid out as early as 2002, aiming at "to move Canada to the front ranks of the world's most innovative industries".

What turns out to be noteworthy in terms of the discussion on the Canadian growth path is that, compared to the OECD and the EU-15 averages, the share of Industry/business sector in both total R\&D expenditures (BERD/Total R\&D Exp.), and in total R\&D production ( $R \& D$ performed by industry-business/ total R\&D Performed) is comparably low. With reference to studies that emphasize the role of the increased BERD intensity on growth, ${ }^{4}$ most commentators interpret that such lower numbers contribute to lower innovation activity, lower R\&D levels, lower investment in machinery and equipment, and "lower than potential" performance of the Canadian economy (Stewart, 2011). On patterns of business innovation, Therrien and Mohnen (2003) report that, in comparison to firms in France, Germany, Spain, and Ireland, Canadian firms display comparably success in innovation and yet, derive a smaller fraction of their sales-revenue from these innovations. Similar concerns are resonated in Banerjee and Robson (2007) and in the 2006 Report of the Institute for Competitiveness and Prosperity (2006:33) which document that in comparison to the US, Canada has lower levels of investment expenditures in the information and communication technology sectors.

One other major point to note in Table 1 is that the percentage of R\&D financed by government has been comparably high in Canada. It is also worth emphasizing that, not only the government support to Industry/business R\&D is high, but government itself is a major producer of R\&D, especially if one takes into account the R\&D produced by Higher Education sector (Table 2). ${ }^{5}$ The average percentage of R\&D undertaken by the Higher Education sector in Canada over 2003-2009 was 34.19\% and has increased to $38.21 \%$ in $2010-13$. This level is almost 20 percentage points higher than the OECD average and 15 percentage points higher than the EU-15 average for 2010-13 period. Similarly, over 2005-2008 period, Canada's government funding to industry/business R\&D was higher than that of US, and in 2008, it was the second highest among the OECD countries (Table 2).

Finally, it should be highlighted that Canada has been identified with having one of the best educated workforces in the world and has been leading the OECD economies in those aged 25-64 who have completed some form of education. However, it has also been noted that despite this first ranking in educated labor force, the employment of highquality labor in Industry/business sector is relatively low. In contrast to this achievement, it is estimated that only $24 \%$ of the Canadian working age population holds a university degree. This rate lags 10 percentage points behind that of the US (Munroe-Blum and MacKinnon, 2009).

\footnotetext{
3 OECD Main Science and Technology Indicators Database.

4 OECD (2003) estimates that an increase in the BERD intensity of $0.1 \%$ raises the real output per capital by $1.2 \%$.

${ }^{5}$ From the point of view of the model setup here, one should note that most universities engaged in R\&D are publicly funded and overseen by federal, provincial or local government in Canada.
}

\section{Model structure}

The model is a direct application of the recent advances in the new growth theory, and is built on the complementarities between R\&Ddriven technological change and human capital acquisition. It simulates the "production-generation of income- and demand" components of the national economy under market constraints in a general equilibrium context. In the model four production industries, labor markets that consist of skilled (human capital) and unskilled (plain) labor force, and private and public sector balances are decomposed by means of algebraic equations. Industrial production increases with expansion of (intermediate) capital varieties. Such expansion is the end result of knowledge capital (R\&D). Knowledge capital investments are performed by oligopolistic entities and oligopolistic profits are used to finance R\&D investments. In the meantime, fixed costs enable increasing returns to scale in expansion of capital varieties and allow growth process to be sustained endogenously.

Furthermore, accumulation of knowledge capital depends on the production of human capital. Following Sequeira (2008, 2011), accumulation of human capital is solved endogenously by inter-household dynamic inter-temporal consumption optimization behavior; and nourished by externality effects of both R\&D production and public expenditures on education. ${ }^{6}$ Thus, three main forces that affect the path of economic growth emerge: knowledge capital accumulation, human capital accumulation, and intensity of public expenditures that affect the pace of accumulation of both of these factors. While the first two depend on rational optimization behavior of private investors under market constraints, the last one is determined by government policy to provide stimulus to R\&D and education (human capital) investments.

The model is presented in more detail in five sub-sections, starting with the final output production, concluding with the conditions for equilibrium and discussion of the macroeconomic identities.

\subsection{Production activities}

The economic structure accommodates four activities in the aggregate, three of which are production activities: (i) production of a final good, $Y$; (ii) production of capital input varieties, $k(i)$ to be used as inputs in the production of $Y$; and (iii) production of R\&D (blueprints, ideas, etc..). A final activity further entails education services (human capital formation).

Final output is produced using plain labor, $L^{Y}$, human capital (skilled labor), $H^{Y}$, and differentiated capital varieties as inputs:

$Y_{t}=A_{Y}\left(L_{t}^{Y}\right)^{\alpha_{L}}\left(H_{t}^{Y}\right)^{\alpha_{H}} \sum_{i=0}^{A_{t}} k_{t}(i)^{\alpha_{k}}$

with $\alpha_{L}+\alpha_{H}+\alpha_{k}=1.0$ to impose constant returns to scale on $Y$. All differentiated capital varieties are of equal quantity and are valued equally. They are produced by symmetric firms where each capital variety is produced by a single monopolistic firm. That is, $k_{t}(i)=k_{t}$ for all $i=1, \ldots, A_{t}$. Therefore, we have at any moment, $\sum_{i=1}^{A_{t}} k_{t}(i)^{\alpha_{k}}=A_{t} k_{t}^{\alpha_{k}}$.

\footnotetext{
${ }^{6}$ Externality effect from R\&D to human capital has been touched upon in literature by Eicher (1996) and Keller (1996). Frantzen (2000), based on the theoretical developments on innovation-driven growth and the discussions about the complementarity between human capital and R\&D, compiles data from 21 OECD economies for the period 1960 to 1990s and estimates (productivity) growth. His estimates indicate significant influence of R\&D (both in growth and in level terms) and also a strong interaction between human capital and the catch-up process. Galor (2005) also emphasizes the idea of technology complementing with skills in the production of human capital or contact with technology through accumulated human capital. As a theoretical contribution, unlike the standard endogenous growth models where the steady state growth rate is not affected by the level of innovative activities but solely on human capital variables, the model of learning with existing knowledge generates a steady state growth rate affected by the level of R\&D (relative to the level of human capital stock) in the economy. See Section 3.5 for further derivations.
} 
Table 1

Selected research and development statistics (2003-09, 2010-13 ${ }^{\mathrm{a}}$ Avg.).

\begin{tabular}{|c|c|c|c|c|c|c|c|c|}
\hline & \multicolumn{2}{|l|}{ Canada } & \multicolumn{2}{|l|}{ USA } & \multicolumn{2}{|c|}{ OECD Avg. } & \multicolumn{2}{|l|}{ EU-15 } \\
\hline & 2003-09 & $2010-13$ & 2003-09 & $2010-13$ & 2003-09 & $2010-13$ & 2003-09 & $2010-13$ \\
\hline \multicolumn{9}{|l|}{ Research and development - expenditures } \\
\hline R\&D expenditures/GDP (\%) & 1.95 & 1.74 & 2.62 & 2.77 & 2.21 & 2.35 & 1.85 & 2.04 \\
\hline R\&D expenditures by Gov./GDP (\%) & 0.63 & 0.60 & 0.80 & 0.87 & 0.66 & 0.70 & 0.63 & 0.68 \\
\hline \% R\&D financed by industry & 49.74 & 47.30 & 63.26 & 58.30 & 62.12 & 59.56 & 54.69 & 55.11 \\
\hline \% R\&D financed by government & 32.27 & 34.69 & 30.74 & 31.52 & 29.75 & 30.15 & 34.21 & 33.52 \\
\hline \multicolumn{9}{|l|}{ Research and development - production } \\
\hline \% R\&D performed by industry/businesses & 55.64 & 51.60 & 69.60 & 68.82 & 67.93 & 67.52 & 63.35 & 63.39 \\
\hline$\%$ R\&D performed by government & 9.69 & 9.73 & 12.12 & 12.53 & 11.82 & 11.71 & 12.73 & 12.07 \\
\hline \% R\&D performed by higher educ. & 34.19 & 38.21 & 13.98 & 14.37 & 17.67 & 18.22 & 22.80 & 23.45 \\
\hline \multicolumn{9}{|l|}{ Research and development - employment } \\
\hline \% Researchers working in businesses & 62.34 & 58.63 & 69.86 & 67.59 & 59.81 & 59.14 & 48.69 & 48.37 \\
\hline \% Researchers working in Government & 6.20 & 6.32 & - & - & - & - & 12.04 & 12.58 \\
\hline \% Researchers working in Higher Educ. & 31.46 & 35.05 & - & - & - & - & 39.27 & 39.05 \\
\hline
\end{tabular}

Source: OECD Main Science and Technology Indicators.

a Depending on data availability.

Table 2

Spending and performance of research and development, Canada, 2012 (million of current dollars)

\begin{tabular}{|c|c|c|c|c|c|}
\hline \multirow[t]{2}{*}{ Sources of funds } & \multicolumn{5}{|l|}{ Performance of R\&D } \\
\hline & Industry/business ent. & Government & Higher education & Other & Total \\
\hline Industry/business ent. & 13,784 & 61 & 980 & 8 & 14,833 \\
\hline Government & 644 & 2840 & 7157 & 103 & 10,744 \\
\hline Higher education & - & - & 2687 & - & 2687 \\
\hline $\begin{array}{l}\text { Other } \\
\text { (Priv. non-profit, foreign etc.) }\end{array}$ & 1725 & - & 1276 & 871 & 3872 \\
\hline Total & 16,153 & 2901 & 12,100 & 982 & 32,136 \\
\hline
\end{tabular}

Source: Statistics Canada-Science Statistics, OECD Main Science and Technology Indicators.

The utilization of plain "labor", on the other hand, follows the now classic convention of Romer (1990) wherein it basically acts as a "shifter" and an instrument to ensure convexity of the production technology (as a fixed endowment). ${ }^{7}$

Hence the $Y$-sector uses $L^{Y}, H^{Y}$, and a series of inputs $\left\{k_{1} \ldots k_{A}\right\}$; where $\{A\}$ is the index of varieties of capital inputs available to this economy. As new research is conducted, the index set $\{A\}$ expands. Following Funke and Strulik (2000) and Sequeira (2008) this is achieved in the R\&D sector as follows:

$A_{t+1}-A_{t}=\varphi H_{t}^{A}$

New research is generated solely by human capital allocated to the production of new ideas (research personnel), $H^{A}$ and excludes decreasing returns as well as the scale effects of $A .{ }^{8}$ The research productivity of each researcher is a factor $\varphi>0$. In what follows, an additional driving source of this economy is the rate of human capital formulation:

$H_{t+1}-H_{t}=\xi H_{t}^{H}+\gamma H_{t}^{\epsilon} A_{t}^{1-\epsilon}$.

In Eq. (3) human capital is a non-market activity and is thought to be "produced" via human capital allocated to education, $H^{H}$, and existing stock of ideas $A$. Past accumulation of human capital is also necessary to generate further human capital.

Generation of $H$ is the end-result of human capital devoted to schooling $\left(\xi H^{H}\right)$ choice by households where the parameter $\xi$ acts as the productivity of schooling and sets the incentive to spend time in education. The second term on the right hand side is a composite of the

\footnotetext{
${ }^{7}$ Here plain labor shouldn't be regarded as a substitute to the formation of the $\mathrm{H}^{Y}$. Plain labor simply refers to a fixed supply of a given amalgam of factors that are not cumulative in the model, and are considered exogenous. As such, human capital ought to be regarded completely independent from the availability of $L^{Y}$.

${ }^{8}$ Such a specification rather than the more general form $A_{t+1}-A_{t}=\varphi H_{t}^{A} A_{t}$ as in Romer (1990), where the R\&D production function admits positive externalities through past research, helps to ensure the steady state.
}

stock of human capital and the existing knowledge (ideas) in the economy. This effect is driven by a productivity parameter, $\gamma$, which measures the relative importance of "learning with existing knowledge". The elasticity parameter $\epsilon$ measures the intensity of human capital to capture the existing knowledge.

As human capital expands, research workers keep on producing new ideas at a constant rate. The growth rate of knowledge production, $g_{t}^{A}$ becomes,

$g_{t}^{A}=\frac{A_{t+1}-A_{t}}{A_{t}}=\varphi \frac{H_{t}^{A}}{A_{t}}$

and remains constant under steady state when the share of human capital allocated to research, $u_{t}^{A}=\frac{H_{t}^{A}}{H_{t}}$, stabilizes. So, defining $H_{t+1} / H_{t}=$ $\left(1+g_{t}^{H}\right)$, growth rate of human capital becomes:

$g_{t}^{H}=\xi \frac{H_{t}^{H}}{H_{t}}+\gamma\left(\frac{A_{t}}{H_{t}}\right)^{1-\epsilon}$

At the balanced growth path, $g_{t}^{H}$ is constant as long as the ratio of total available number of ideas to the stock human capital remain fixed. These formulations further necessitate that a steady state solution with a constant rate of growth requires a constant allocation of $H_{t}$ along its components. Hence, under long run equilibrium, infinitely-lived people will dedicate in each period a constant amount of time-share between working and schooling.

The final good sector works under perfectly competitive conditions. The producer hires both types of labor and the capital varieties up to the point where the value of the marginal product of each factor is equated to its wage and rental costs, respectively. Therefore, labor is demanded according to $w_{t}^{L}=P_{t}^{Y} \partial Y_{t} / \partial L_{t}^{Y}$. Human capital demand is similar with $w_{t}^{H}=P_{t}^{Y} \frac{\partial Y_{t}}{\partial H_{t}^{Y}}$. 
Each capital variety $i$ is demanded along the functions:

$p_{t}^{k}(i)=P_{t}^{Y} \alpha_{k}\left(L_{t}^{Y}\right)^{\alpha_{L}}\left(H_{t}^{Y}\right)^{\alpha_{H}} k_{t}(i)^{\alpha_{k}-1} i=1, \ldots, A_{t}$.

Finally, in the R\&D sector, given public subsidies on R\&D costs, human capital is demanded so as to satisfy its marginal productivity condition: ${ }^{9}$

$w_{t}^{H}=P_{t}^{A} \varphi$

Note that, competitive conditions in factor markets necessitate that wage costs of human capital are equated across its uses in the R\&D sector and in the final good production sector. Thus, $w_{t}^{H}=P_{t}^{A} \varphi=P_{t}^{Y} \alpha_{H} Y_{t} / H_{t}^{Y}$.

\subsection{Differentiated capital and investment decision}

"Capital" is modeled here as a heterogeneous input which accumulates by the varieties, $k(i)$. The intermediate firm purchases 'blueprints' (the technological knowledge generated in the R\&D sector) and according to the instructions therein, produces a new capital variety. The number of new capital varieties produced at period $t$ is equal to the number of new blueprints produced in the same period, $A_{t}$. Ignoring depreciation, the number of accumulated capital varieties in the economy at time $t$ is equal to the number of blueprints available in the economy. Each new capital input $k(i)$ is produced by using real resources at a constant ratio, $\eta$, where $\eta$ acts as the 'input-output coefficient' to produce one unit of $k(i)$. Costs of $\eta$ is the rental price, $r$ - the interest rate in this economy.

Now, observe that as the intermediate producer has purchased the R\&D blueprints, these research costs totaling $P_{t}^{A}$, have to be borne up-front by the intermediate capital variety firm. Thus, the expression $P_{t}^{A} \Delta A_{t}$ becomes the fixed costs of production of $k_{t}(i)$, and leads to increasing returns in its production. Since the $i$-th firm has monopoly rights in the production of $k_{t}(i)$, it acts monopolistically in the capital goods market. Taking the demand function for $k_{t}(i)$ from the final good producer (6) as given, each monopolist seeks to maximize the monopoly profits:

$\max _{k_{t}(i)} \pi_{t}(i)=p_{t}^{k}(i) k_{t}(i)-\eta r_{t} k_{t}(i)-P_{t}^{A} \Delta A_{t}$.

The solution of (8) reveals that the profit maximizing price $p_{t}^{k}(i)$ is given by a 'mark-up' over the marginal costs, $\eta r_{t}$. Using the demand for $k_{t}(i)$ from the final good producer's decision we have the following optimal pricing rule for the profit maximizing monopolist:

$P_{t}^{Y} \alpha_{k}^{2}\left(L_{t}^{Y}\right)^{\alpha_{L}}\left(H_{t}^{Y}\right)^{\alpha_{H}} k_{t}(i)^{\alpha_{k}-1}=\eta r_{t}$.

Therefore, optimal quantity of the capital variety is set via:

$k_{t}(i)=\left[\frac{P_{t}^{Y} \alpha_{k}^{2}\left(L_{t}^{Y}\right)^{\alpha_{L}}\left(H_{t}^{Y}\right)^{\alpha_{H}}}{\eta r_{t}}\right]^{\frac{1}{1-\alpha_{k}}}$.

As common in the R\&D-driven endogenous growth models, the size of the monopolistic mark-up for each capital variety producer is $1 / \alpha_{k}$ over the marginal costs $\left(\eta r_{t}\right)$ :

$p_{t}^{k}(i)=\frac{P_{t}^{Y} \eta r_{t}}{\alpha_{k}}$

Since all firms are symmetric and they all set the same price (Eq. (10)), to sell their respective capital varieties we will set $p_{t}^{k}(i)=$ $p_{t}^{k}$ and $k_{t}(i)=k_{t}, \forall i$. Under these conditions the maximum profit is expressed as:

$\pi_{t}^{\max }\left(k_{t}\right)=p_{t}^{k} k_{t}-\eta r_{t} k_{t}=\left(p_{k}-\eta r_{t}\right) k_{t}$

\footnotetext{
9 In case of an R\&D subsidy, the equation becomes: $w_{t}^{H}=\frac{P_{t}^{A} \varphi}{\left(1-s^{R}\right)}$, where $s^{R}$ represents the subsidy rate to accumulate human capital in the R\&D sector.
}

Since $r_{t}=\frac{\alpha_{k} p_{t}^{k}}{\eta}$ from above, we can express maximum profit of the monopolists as:

$\pi_{t}^{\max }\left(k_{t}\right)=\left(1-\alpha_{k}\right) p_{t}^{k} k_{t}$

The monopoly firms have a forward-looking behavior. That is, they make investment decisions on developing new blueprints and producing new capital varieties so as to maximize the long-run expected returns from an infinite stream of monopoly profits. In particular, the expected returns from investment must be comparable with those from holding a "safe" asset such as bonds or bank deposits. Thus, asset market equilibrium requires, for any point in time, that the following non-arbitrage condition holds:

$\pi_{t}+\left(P_{t}^{A}-P_{t-1}^{A}\right)=r_{t} P_{t-1}^{A}$

where the term $\left(P_{t}^{A}-P_{t-1}^{A}\right)$ denotes changes in the valorization of the $i-t h$ firm over time. In equilibrium, the value of the firm is equal to aggregate investment expenditures, which includes the cost of developing a new blueprint $\left(P_{t}^{A}\right)$, plus the material costs of investment goods. Imposition of the transversality condition to rule out speculative bubbles gives $P_{t}^{A}=\sum_{t=0}^{\infty} R(t) \pi_{t} \cdot{ }^{10}$

The above no-arbitrage condition can also be expressed more succinctly as:

$\left(1+r_{t}\right) P_{t-1}^{A}=\pi_{t}+P_{t}^{A}$

Finally, note that investment expenditures in this model are destined for two purposes: generating new research, and producing new capital varieties:

$I_{t}^{D}=\eta\left[\left(A_{t+1}-A_{t}\right) k_{t}+\left(k_{t+1}-k_{t}\right) A_{t}\right]$

\subsection{Consumption, saving and human capital accumulation decisions}

Households are endowed with human capital, $H_{t}$ each period, and decide to allocate it among three uses, final good production, knowledge production and further human capital formation:

$H_{t}=H_{t}^{Y}+H_{t}^{H}+H_{t}^{A}$

where $\left(H_{t}-H_{t}^{Y}\right)$ is associated with a wage rate $w_{t}^{H}$ and $H_{t}^{H}$ may be subsidized through $s^{H} w_{t}^{H}$, with $s^{H}>0$. The representative household maximizes a utility function of the form:

$\max U_{0}=\sum_{t=0}^{\infty} \beta^{t} \frac{c_{t}^{1-\theta}-1}{1-\theta}$

subject to

$\sum_{t=0}^{\infty} R(t) P_{t}^{C} c_{t}=T W_{0}$

$H_{t+1}-H_{t}=\xi H_{t}^{H}+\gamma H_{t}^{\epsilon} A_{t}^{1-\epsilon}$

with control variables $c_{t}>0$ and $H_{t}^{H} \geq 0$. Here, $T W_{0}$ is the total wealth, which includes the present value of period-wise income. $Y_{t}^{H}=\left(1-t^{Y}\right)$ $\left[w_{t}^{H}\left(H_{t}-H_{t}^{H}\right)+s^{H} w_{t}^{H} H_{t}^{H}+w_{t}^{L} L_{t}^{Y}+p_{t}^{k} k_{t} A_{t}\right]$ is the private household disposable income composed of returns to primary factors of production and the value of monopoly firms of capital variety.

\footnotetext{
10 That is, the value of the monopoly firm is equal to the discounted value of the stream of monopoly profits, where $R(t)$ is a discount factor defined according to $R(t)=\prod_{s=0}\left(1+r_{t}\right)^{-1}$.
} 
For an interior solution, the F.O.C.'s associated with the maximization problem above are twofold:

$\beta\left(1+r_{t+1}\right)\left(\frac{c_{t+1}}{c_{t}}\right)^{\theta}=\frac{P_{t+1}^{C}}{P_{t}^{C}}$

$\frac{w_{t}^{H}}{w_{t+1}^{H}}=\frac{1}{1+r_{t+1}}\left(\frac{\xi}{\left(1-s^{H}\right)}+1+\gamma \epsilon\left(\frac{H_{t+1}}{A_{t+1}}\right)^{1-\epsilon}\right)$ with $H^{H}>0$.

The first condition above is the discrete version of the standard Ramsey rule. The second equation implies that the growth rate of wages must be sufficiently high enough compared to the interest rate to ensure positive investment in human capital.

Using $\frac{w_{t}^{H}}{\varphi}=P_{t}^{A}$ from Eq. (7), we get $\frac{w_{t+1}^{H}}{w_{t}^{H}}=\frac{P_{t+1}^{A}}{P_{t}^{A}}$. The rate of growth of $P_{t}^{A}$ above is narrated in the no-arbitrage condition (13). Inserting in the equations for $\pi_{t}$ and $P_{t}^{A}$ and equating the two expressions for $\frac{w_{t+1}^{H}}{w_{t}^{H}}$, give us:

$1+\frac{1-\alpha_{k}}{\alpha_{H}} \varphi \alpha_{k} \frac{u_{t+1}^{Y} H_{t+1}}{A_{t+1}}=\frac{\xi}{\left(1-S^{H}\right)}+\left(1+\gamma \epsilon\left(\frac{H_{t+1}}{A_{t+1}}\right)^{(1-\epsilon)}\right)$.

Now assume that we denote the share of $H_{t}$ allocated to final goods production, $H_{t}^{Y}$ as $u_{t}^{Y}$. The equation above should provide the value of $u_{t+1}^{Y}$, given $H_{t+1} / A_{t+1}$ which is critical in terms of the allocation of human capital to different sectors of the economy. It also implies $u_{t+1}^{Y}=u^{Y}$ at the steady state.

\subsection{Export and import functions and balance of payments}

The representative final good producer has the following production possibility boundary between exports, $E_{t}$ and domestic sales, $D C_{t}$ (the constant elasticity of transformation - CET frontier):

$X_{t}=\bar{Z}_{X}\left(\nu E_{t}^{(1+\sigma) / \sigma}+(1-\nu) D C_{t}^{(1+\sigma) / \sigma}\right)^{\sigma /(1+\sigma)}$.

In equilibrium, the ratio of exports to domestic good becomes:

$\frac{E_{t}}{D C_{t}}=\left(\frac{P_{t}^{E}}{P_{t}^{D}}\right)^{\sigma}\left(\frac{1-\nu}{\nu}\right)^{\sigma}$.

Import decisions are derived from the Armingtonian composite commodity specification, where imports $M_{t}$, and domestic good, $D C_{t}$

$C C_{t}=\bar{Z}_{C C}\left(\kappa M_{t}^{(\psi-1) / \psi}+(1-\kappa) D C_{t}^{(\psi-1) / \psi}\right)^{\psi /(\psi-1)}$.

In equilibrium the ratio of imports to the domestic good becomes

$\frac{M_{t}}{D C_{t}}=\left(\frac{P_{t}^{D}}{P_{t}^{M}}\right)^{\psi}\left(\frac{1-\kappa}{\kappa}\right)^{\psi}$

where $P_{t}^{M}=\left(1+t^{m}\right) P_{t}^{W M}$ and $P_{t}^{E}=P_{t}^{W E}$ with $t^{m}$ representing tariff rate at period $t$. We assume that the economy has balanced trade in each time period.

\subsection{National income identities and equilibrium growth}

Intra-temporal equilibrium requires that at each time period, (i) demand for primary factors $\left(L^{Y}, H^{A}, H^{Y}\right)$ equals their respective supplies; (ii) human capital allocation among final good production, $Y$, R\&D production, $\Delta A$, and education, $\Delta H$ exhausts its total supply; (iii) domestic demand plus export demand for the output of each sector equal its supply; (iv) the output of R\&D, that is the number of new blueprints, equals to the number of new capital varieties invested; (v) household savings equal investment - costs of new blueprints plus costs of investment goods in capital variety production; (vi) the value of total exports equals to the value of total imports; and (vii) the government budget is satisfied.

Gross domestic product (GDP) at factor cost (exclusive of production taxes) is the sum of value added of the final good, human capital expenditures, and the R\&D sectors:

$$
\begin{aligned}
G D P_{t} & =P_{t}^{Y} Y_{t}+P_{t}^{A} \Delta A_{t} \\
& =w_{t}^{L} L_{t}^{Y}+w_{t}^{H}\left(H_{t}^{Y}+H_{t}^{A}\right)+\sum_{i=1}^{A_{t}} p_{t}^{k}(i) k_{t}(i) .
\end{aligned}
$$

Using $\sum_{i=1}^{A_{t}} p_{t}^{k}(i) k_{t}(i)=p_{t}^{k} A_{t} k_{t}$, which in turn will be equal to $\alpha_{k} P_{t}^{Y} Y_{t}$, the identity in Eq. (25) can also be written as:

$p_{t}^{k} A_{t} \cdot k_{t}=\alpha_{k}\left(G D P_{t}-P_{t}^{A} \Delta A_{t}\right)$.

Furthermore, using the definition of profits from Eq. (12), the GDP identity can also be written as:

$P_{t}^{Y} Y_{t}+P_{t}^{A} \Delta A_{t}=w_{t}^{L} L_{t}^{Y}+w_{t}^{H}\left(H_{t}^{Y}+H_{t}^{A}\right)+A_{t} \frac{\pi}{\left(1-\alpha_{k}\right)}$.

In the steady state equilibrium all quantity variables grow at a constant rate which is proportional to the growth rate of human capital formation. All prices, including prices for final goods produced and consumed domestically, the unit cost of the R\&D output, differential capital varieties, and the interest rate grow at a constant rate in the steady state. Also, the allocation of $H_{t}$ among its uses will be constant; hence, given $H_{t}^{Y}=u^{Y} H_{t}, H_{t}^{A}=u^{A} H_{t}$ and $H_{t}^{H}=u^{H} H_{t}$, with $u^{A}+u^{H}+u^{Y}=1$.

Based on these specifications, the growth rates $g_{t}^{H}$ and $g_{t}^{A}$ imply that at steady state $H_{t} / A_{t}$ is constant. Combining the definitions of $g_{t}^{H}$ and $g_{t}^{A}$, we have $g^{H}=g^{A}$ at the steady state.

Perfect labor mobility implies that $w_{t}^{H}$ in R\&D sector is the same as the $w_{t}^{H}$ in the final goods sector. Equating the two, we have:

$P_{t}^{A}=\frac{\alpha_{H} L_{t}^{\alpha_{L}} H_{t}^{\gamma_{H}-1} A_{t} k_{i}^{\alpha}}{\varphi}$

Therefore:

$\left(1+g_{t}^{P_{A}}\right)=r_{t}-\frac{\left(1-\alpha_{k}\right)}{\alpha_{H}} \alpha_{k} \frac{H_{t}^{Y}}{A_{t}} \varphi$

Since we now have the solution for $P_{t}^{A}$ above, we can also derive the growth rate $P_{t}^{A}$ at the steady state as:

$\left(1+g^{P A}\right)=\left(1+g^{H}\right)^{\frac{\alpha_{H}}{1-\alpha_{k}}}$

Finally, since $Y_{t}=A_{Y} L_{t}^{Y \alpha_{L}} H_{t}^{Y \alpha_{H}} \sum_{i=0}^{A_{t}} k_{t}(i)^{\alpha_{k}}$, we have the following relationship between the rate of growth of output and the rate of growth of human capital at the steady state as:

$\left(1+g^{Y}\right)=\left(1+g^{H}\right)^{\frac{1+\alpha_{H}-\alpha_{k}}{1-\alpha_{k}}}$

\section{Dynamic effects of the selected public policies to promote growth}

Now we turn to an analysis of the basic mechanisms of growthgenerating dynamics of the model incorporating both accumulation of R\&D and accumulation of human capital. In the words of MunroeBlum and MacKinnon (2009:10), our main task is to contribute to building of a shared platform of an innovation society that would provide a sense of common purpose for private corporate sector - university and government partnerships to address the main symptomatic problem: bridge the gap between research and innovation. Taking into 
account the "partial excludability" property of "knowledge" leads, in the absence of public intervention, to under-investment in the provision and acquisition of new technologies. Since the framework employed here aims at enhancing the complementarity between human capital and the R\&D activities, and the externalities associated with the accumulation of both, we first explore the basic mechanisms of "correcting" the "market failures" toward superior outcomes.

\subsection{Effects of human capital and RED promoting policies}

First, we focus on the basic mechanisms of growth generating dynamics of the model by investigating two key policy instruments. Each instrument is designed to enhance growth via stimulating the accumulation process of factors affecting the growth rate of the economy each period. Specifically, we study subsidization of education (subsidy on the buildup of human capital through skill-accumulation function via $s^{H}$ ) and contrast it with subsidization of the R\&D activities (subsidy on the input costs to R\&D via $s^{R}$ ). The first policy experiment is designed to analyze the households' response to allocate human capital among different sectors and activities in the economy under the conditions of increased reward to education activities. Since the instrument, $s^{H}$, enters into representative household's intertemporal maximization problem, we shall observe the effects on the derivation of the future wages both in the final goods and the R\&D sectors of the economy and the trade-offs embedded. The other policy instrument analyzed at this stage is designed to promote R\&D activities. It is implemented through the addition of an ad valorem subsidy to the input cost of the production of new R\&D.

In order to set up an environment to "suitably" compare and contrast both the short-run and the long-run effects of alternative subsidy schemes, we fix the total subsidy financing to an amount that would correspond to $0.5 \%$ of the benchmark GDP in every period. For each subsidy type we calculate the corresponding subsidy rate and document the results as averages below. The burden of the cost of each targeted policy is born as lump-sum expenditures from the government budget, affecting public consumption under the current model closure. ${ }^{11}$

Table 3 documents both the short-run and the long-run comparisons for a chosen set of variables under alternative scenarios. ${ }^{12}$ Figs. $1-7$, in addition, display the transition dynamics for selected variables. At a first glance, Table 3 reveals a general observation that education subsidy provides more favorable results with respect to steady-state growth rates, both in terms of output and knowledge stock of the economy. Such a result, of course is related to changes in the ratio of total human capital to total $R \& D(H / A)$, and therefore, allocation of human capital among different sectors and activities in the economy. A subsidy to education, bidding more human capital to skill-accumulation activities, leads to a higher stock of human capital and lower stock of R\&D, compared to both the benchmark and the R\&D subsidy scenario. The long-run equilibrium under this instrument is achieved at a $H / A$ ratio $2.9 \%$ higher than the benchmark, and $22.0 \%$ higher than the R\&D subsidy cases. Likewise, under the human capital subsidy scheme, share of education in the allocation of human capital is $19.0 \%$; under R\&D subsidy scheme it drops to $7.8 \%$. Concomitantly, the share of R\&D sector in the allocation of total human capital is $28.9 \%$ under education subsidy and it increases to $33.6 \%$ under R\&D subsidy.

On the other hand, taking into account the transition dynamics, one could observe interesting trade-offs of the adjustment processes. First, we see that the education subsidy induces relatively large re-

\footnotetext{
${ }^{11}$ Here, we report the total government revenues raised under alternative subsidy schemes and the portion left after the budgeting of alternative subsidy programs; which we refer as "government consumption". Hence, we are able to explicitly follow the impact of differentiated transition dynamics on the public sector accounts. We repeat each scenario under which the "government consumption" raised is provided as lump-sum transfers to agents that represent welfare programs.

12 The upper panel of Table 3 provides the steady state implications of each scenario while the lower panel illustrates two points referring to immediate and medium-term responses (of selected variables) during the transition phase.
}

allocation effects on primary resources, the greater part of the adjustment occurs during the initial periods. Immediately, the human capital allocated to education increases by $49.5 \%$. After this initial swing, compared to the benchmark, the adjustment dynamics reveal an average increase of $10.9 \%$ for this variable, over the medium-term. Thus, although education subsidy displays higher growth rates with respect to benchmark and R\&D subsidy scenarios at the steady state, it initially creates a large negative effect on the growth path of the economy. Such observation is basically due to the allocation of human capital away from marketed activities, and seems to take quite long time to be recovered.

The impacts of slow convergence to the steady state under education subsidy is also apparent in the dynamics of output (Fig. 3) and consumption (Fig. 7). Growth rate of the economy under education subsidy is observed to recover only slowly and the effects of the initial negative swing of consumption appears to dominate the long transition period. Then again, as the long run dynamics settle, the higher steady state growth rate under education subsidy eventually takes over. In summary, the education subsidy scheme, promises a higher long-run growth rate, yet its transition path displays notably negative effects for the current generations as also revealed by the variables corresponding to welfare (consumption, saving utility index) in Table 3.

The education subsidy in the model is represented by a direct transfer of income from the government budget to the human capital accumulation activity. An announcement of subsidy to human capital accumulation activity basically drives resources away from the R\&D activity, leaving the amount allocated to final goods sector only slightly lower. As a result, the accumulation of human capital in the economy continues at a higher pace than the accumulation of R\&D (Figs. 1, 2). The output growth, which is dependent on both the accumulation of $\mathrm{R} \& \mathrm{D}$ and the human capital allocated to final goods sector is adversely affected. Although the rate of growth of GDP quickly bounces back, the immediate negative effect of bidding resources away from the other sectors of the economy is felt during a long transition period.

On the other hand, the announcement of an R\&D subsidy as reflected in the reduction of cost of input (wage of human capital, $w^{H}$ ) employed by the producers of R\&D, advances the R\&D sector to pull primary resources away from the other sectors of the economy. Under such an instrument, the demand for R\&D activities is increased to a higher steady-state level, compared to the benchmark and the education subsidy scenarios. On the other hand, total human capital levels are lower under this scenario. As a result, the steady state human capital - R\&D ratio under this policy is substantially lower than both the benchmark (15.6\%) and the education subsidy policy (18.0\%).

As the R\&D production cost is reduced by the subsidy, the stream of monopoly rents, acquired from the property rights of the blueprints increases. Such an increase stimulates further incentives for the production of capital, as new firms are attracted by increased profits. So, the subsidy to the cost of R\&D production pulls down the price of R\&D and begins to encourage an upward shift in the demand for differentiated capital (new information technologies) production sector, leading to higher level of production of differentiated capital in the economy, both during latetransition and at the steady state (See Table 3 and Fig. 4). It is partially due to this stimulation of the activity in the final goods sector that keeps the wage rate of human capital higher under this scenario.

Fig. 3 displays real GDP under alternative subsidy schemes. The initial negative effect of the education subsidy on the productive sectors keeps such a subsidy plan at a lower path compared to base-run and the path under R\&D subsidy. Although the growth rate recovers in the long-run, the GDP and consumption paths under education subsidy are much less favorable for the current generations. On the other hand, the R\&D subsidy scheme creates a more direct effect in terms of the allocation of resources in the economy, leading to a higher average growth rate during transition toward the new steady state. It is because of the differences in the growth dynamics of the economy under different scenarios that leads to differentiated burden for current and future generations of the same amount of subsidy as a ratio to GDP. 
Table 3

Effects of different subsidy schemes in the short-run and in the long-run.

\begin{tabular}{|c|c|c|c|c|c|c|c|c|c|}
\hline \multirow[t]{2}{*}{ Steady-state implications } & \multirow[b]{2}{*}{ Benchmark } & \multicolumn{2}{|c|}{ (Average $6.67 \%$ points) } & \multicolumn{2}{|c|}{ (Average $4.25 \%$ points) } & \multicolumn{2}{|c|}{ (Average $4.19 \%$ points) } & \multicolumn{2}{|c|}{$\begin{array}{l}\text { (Avg. } 2.60 \% \text { sub. human } \\
\text { cap. \& avg. } 3.66 \text { sub. R\&D) }\end{array}$} \\
\hline & & \multicolumn{2}{|c|}{ Subsidizing human cap. } & \multicolumn{2}{|c|}{ Subsidizing R\&D } & \multicolumn{2}{|c|}{ Investment subsidy } & \multicolumn{2}{|c|}{ Optimal subsidy scheme } \\
\hline gy (\%) & 3.000 & \multicolumn{2}{|l|}{3.049} & \multicolumn{2}{|l|}{2.998} & \multicolumn{2}{|l|}{3.000} & \multicolumn{2}{|l|}{3.050} \\
\hline gA (\%) & 2.080 & \multicolumn{2}{|l|}{2.114} & \multicolumn{2}{|l|}{2.078} & \multicolumn{2}{|l|}{2.079} & \multicolumn{2}{|l|}{2.115} \\
\hline $\mathrm{gPA}(\%)$ & 0.901 & \multicolumn{2}{|l|}{0.916} & \multicolumn{2}{|l|}{0.903} & \multicolumn{2}{|l|}{0.901} & \multicolumn{2}{|l|}{0.902} \\
\hline Growth rate of total differentiated capital (\%) & 3.000 & \multicolumn{2}{|l|}{3.049} & \multicolumn{2}{|l|}{2.998} & \multicolumn{2}{|l|}{3.000} & \multicolumn{2}{|l|}{3.050} \\
\hline $\mathrm{H} / \mathrm{A}$ & 1.024 & \multicolumn{2}{|l|}{1.053} & \multicolumn{2}{|l|}{0.864} & \multicolumn{2}{|l|}{1.024} & \multicolumn{2}{|l|}{0.889} \\
\hline uy (\%) & 53.2 & \multicolumn{2}{|l|}{52.1} & 58.6 & & 53.2 & & 57.8 & \\
\hline $\mathrm{uA}(\%)$ & 29.2 & 28.9 & & 33.6 & & 29.2 & & 33.1 & \\
\hline $\mathrm{uE}(\%)$ & 17.6 & 19.0 & & 7.8 & & 17.6 & & 9.1 & \\
\hline Utility (\% deviation from benchmark) ${ }^{\mathrm{a}}$ & & 0.061 & & 0.053 & & 0.059 & & 0.075 & \\
\hline Transition Implications & & Subsidizing & human cap. & Subsidi & zing R\&D & Investme & nt subsidy & Optimal sul & sidy scheme \\
\hline \% Deviation from benchmark & & Immediate & Medium run & Immediate & Medium run & Immediate & Medium run & Immediate & Medium run \\
\hline GDP & & -6.873 & 0.992 & 2.123 & 1.038 & 3.723 & 1.032 & 1.884 & 1.026 \\
\hline Private income & & -6.646 & -0.291 & 2.219 & 3.772 & 3.865 & 3.243 & 2.094 & 2.791 \\
\hline Private consumption & & 0.121 & -0.324 & 1.004 & 3.843 & 0.228 & 3.920 & 0.909 & 2.856 \\
\hline Private saving & & -14.248 & -0.309 & 5.678 & 3.510 & 6.251 & 1.184 & 4.943 & 2.529 \\
\hline Total R\&D (A) & & -1.434 & -0.402 & 0.945 & 3.898 & 0.700 & -0.282 & 0.864 & 2.713 \\
\hline Total human Cap. (H) & & 0.495 & 2.590 & -0.288 & -4.250 & -0.248 & -0.379 & -0.264 & -2.880 \\
\hline Price of $R \& D\left(P^{A}\right)$ & & 0.517 & -1.393 & -2.766 & -0.762 & 0.091 & 3.378 & -1.982 & -0.957 \\
\hline Human capital alloc. to educ. $\left(\mathrm{H}^{\mathrm{H}}\right)$ & & 61.178 & 10.888 & -31.430 & -27.937 & -21.133 & -0.381 & -25.235 & -21.604 \\
\hline Human capital alloc. to $\mathrm{R} \& \mathrm{D}\left(\mathrm{H}^{\mathrm{A}}\right)$ & & -33.584 & 1.473 & 20.296 & 3.387 & 10.619 & -0.553 & 16.314 & 3.299 \\
\hline Human capital alloc. to final goods $\left(\mathrm{H}^{\mathrm{Y}}\right)$ & & -0.864 & 0.455 & -1.293 & -0.602 & 0.695 & -0.283 & -1.109 & -0.074 \\
\hline Government revenues & & -2.088 & -0.664 & 0.614 & 3.495 & 1.490 & 3.261 & 0.609 & 2.476 \\
\hline Government consumption & & -4.426 & -3.002 & -1.724 & 1.157 & -0.848 & 0.924 & -1.729 & 0.138 \\
\hline Utility (welfare index) & & 0.003 & -0.048 & 0.077 & 0.168 & 0.033 & 0.176 & 0.066 & 0.177 \\
\hline
\end{tabular}

a Utility Index takes into account the consumption path during both the transition and the steady state.

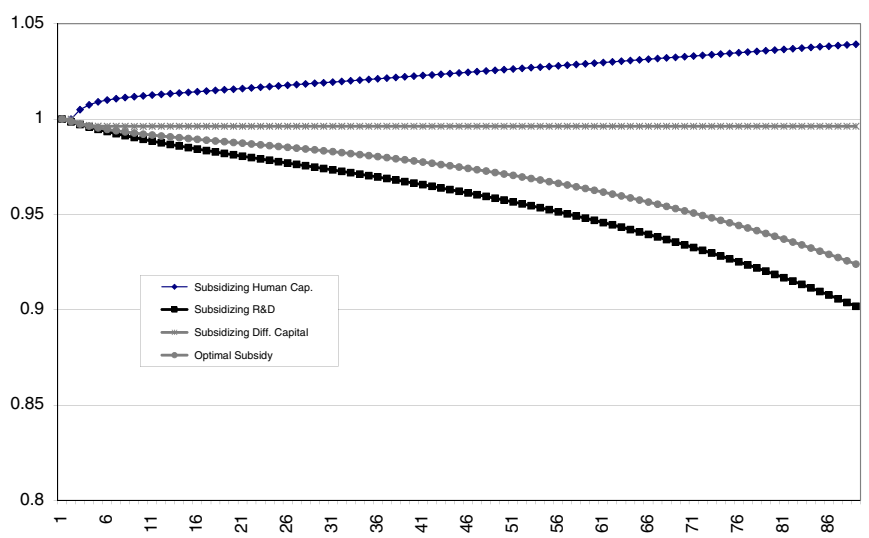

Fig. 1. Total human capital under different subsidy schemes (w.r.t. base run).

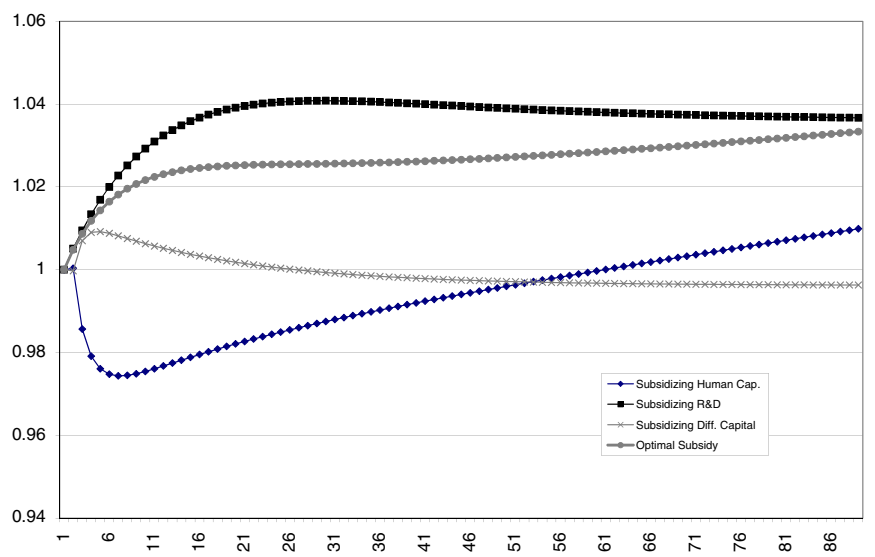

Fig. 2. Total R\&D under different subsidy schemes (w.r.t. base run).

\subsection{Subsidizing differentiated capital}

Observing the importance of the accumulation of differentiated capital both on the generation of transition dynamics and on the steady state path of the economy, we also shortly analyze promoting growth through a subsidy to employers of differentiated capital. In this experiment, we lower the marginal cost of differentiated capital in terms of final goods allocated to transforming R\&D to a productive technology. Such a subsidy is expected to provide incentives to increase the demand for differentiated capital, which in turn would have a stimulus on the accumulation of capital stock and the R\&D stock of the economy.

Note that in such an environment the mechanism of re-allocation of resources in the economy is different from either the education subsidy or the R\&D subsidy scenarios. In case of education or R\&D subsidy, the subsidized sector pulls the resources away from the other activities in the economy. In case of subsidy to the cost of differentiated capital, on the other hand, the direct beneficiary is the final goods sector. The demand for factors of production in the final good sector increases. Thus, during the transition period, growth is primarily achieved both by the increased production of each of the existing capital variety and also by the increased number of varieties (see Eq. (9)). Such dynamics is noticeable in the rising level of human capital allocated both to final goods and to the R\&D production sectors. However, throughout the further stages of transition, because now total human capital accumulated through education is lower, the levels of human capital allocated to each sector display a lowered trend compared to the education subsidy scenario and the benchmark. ${ }^{13}$ In the long run, aggregate human capital accumulation remains slightly below the benchmark.

Nonetheless, the reduced cost of differentiated capital helps the economy to support a higher level of production, consumption and saving, due

\footnotetext{
13 It is mainly because of this level effect of the decreased human capital production in the economy that we observe the initial demand-pull effect of the final goods sector on R\&D production cannot be sustained in the medium-to-long run under this scenario (Fig. 2).
} 


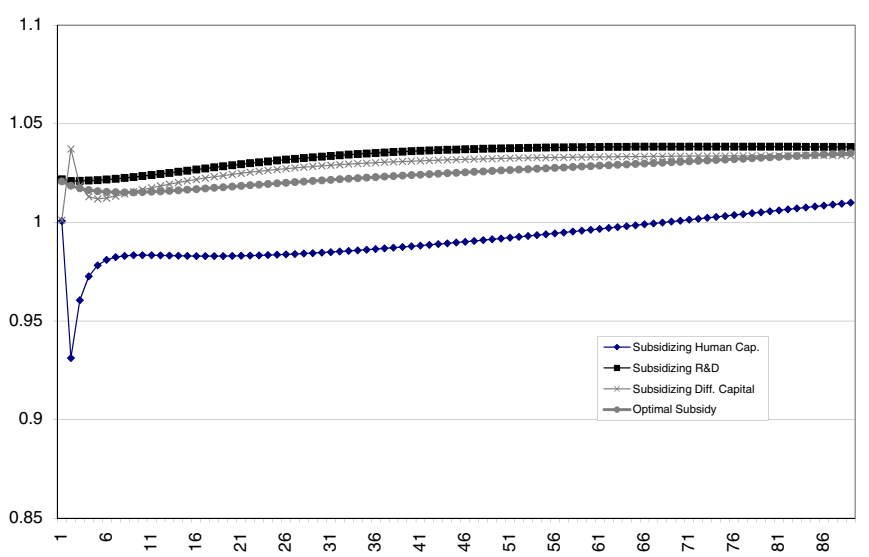

Fig. 3. GDP under different subsidy schemes (w.r.t. base run).

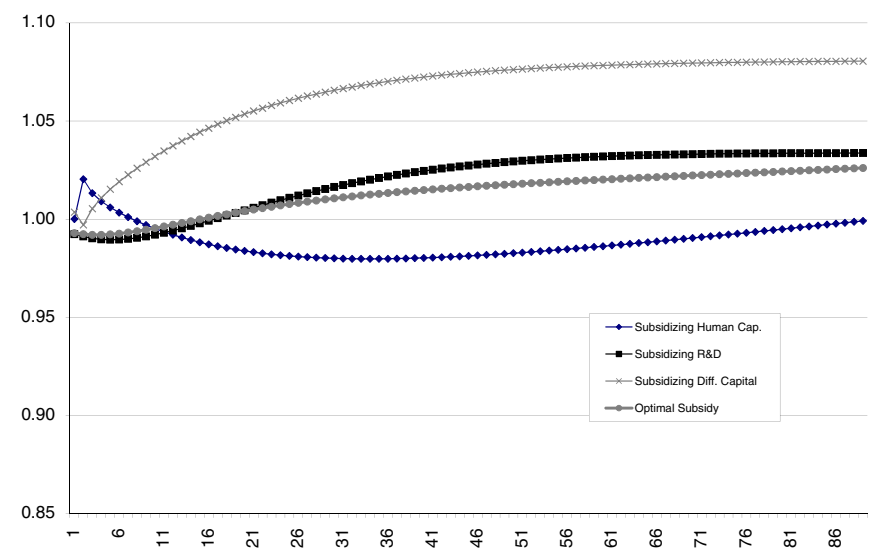

Fig. 4. Total differentiated capital under different subsidy schemes (w.r.t. base run).

to a much favorable environment in terms of the returns to factors of production and the private household income. Such an elevated path during long transition turns out to be the main reason why, compared to the benchmark case, steady state welfare implications of this policy is higher.

4.3. Dynamics of adjustment under education, R\&D and differentiated capital subsidy scenarios

The working of different adjustment mechanisms through the transition path, under alternative policy scenarios are most visible in the price of human capital as a factor of production $\left(w^{H}\right)$ and the price of R\&D $\left(P^{A}\right)$. Figs. 5 and 6 display the transition dynamics of these two

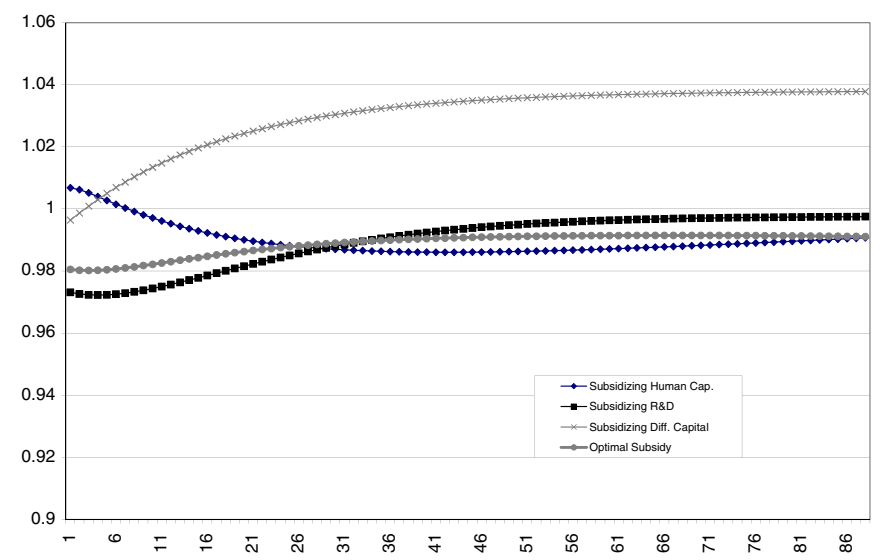

Fig. 5. Price of R\&D under different subsidy schemes (w.r.t. base run).

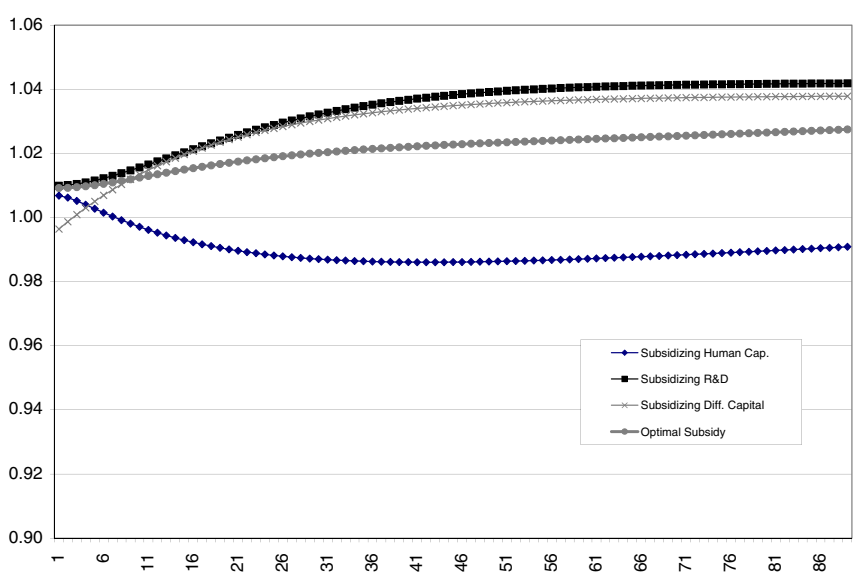

Fig. 6. Wage rate (of human capital) under different subsidy schemes (w.r.t. base run).

variables over periods $1-30$. In order to present the background for the calculations of the welfare index, Fig. 7 displays the private consumption dynamics over the same period.

As the education subsidy bids the human capital toward the skill accumulation activity, the market price of the human capital as well as the price of R\&D are initially highest for this scenario. As human capital supply increases, it turns out that the returns to human capital as well as returns to R\&D take the lowest values. As subsidy to differentiated capital creates higher demand for R\&D and subsidization of the human capital in the $R \& D$ sector creates higher demand for human capital in $R \& D$, the price of $R \& D$ increases the highest under the first and the price of human capital gets the highest under the second scenarios, throughout the transition (see Table 3).

We find that under education subsidy scenario, the welfare index changes sign during the course of adjustment toward steady state. The negative effect of significantly lower production, income and consumption throughout the transition period becomes more pronounced as the economy moves toward the new steady state (Fig. 7). On the other hand, the R\&D subsidy scheme provides a higher level of consumption right away, during transition and is able to provide higher level of consumption relative to the benchmark reaching to the new steady state. We also find that, under the capital accumulation subsidy scheme, the immediate impact of increased saving is transformed into a higher consumption path through the transition.

\subsection{Optimal subsidy structure}

Given that the model structure incorporates a set of market failures/ externalities associated with both the accumulation of human capital and R\&D, one evident question points to the optimal subsidy structure. ${ }^{14}$ Here, given the structure of the public revenue raising policy instruments as implemented under the fixed ratio of $0.5 \%$ of benchmark GDP, we search for the welfare maximizing combination of education and R\&D subsidies. We report the corresponding values of the selected variables and the welfare results under the "Optimal Subsidy" column in Table 3 and Figs. 1-7. Fig. A-1 in Appendix A also illustrates the outcome of a search algorithm that reports the maximum welfare (as \% deviations from benchmark) for each $\left(s^{H}, s^{R}\right)$ pair.

The optimal subsidy scheme is associated with a human capital level marginally higher than the R\&D subsidy scheme and lower than the education subsidy policy. Therefore, the $H / A$ at the steady state is attained at a level higher than the first and lower than the second (Table 3, Figs. 1-2). Through both types of subsidies, the output, final income and consumption are stimulated, albeit rather slowly. Under the optimal subsidy

\footnotetext{
${ }^{14}$ We thank to the anonymous referee for bringing up the discussion on the optimal design of subsidy policies.
} 


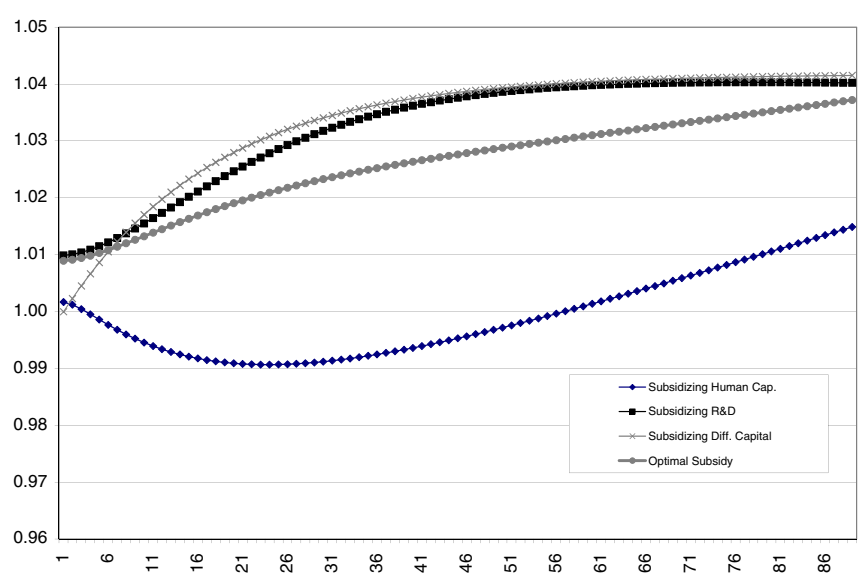

Fig. 7. Private consumption under different subsidy schemes (w.r.t. base run).

structure, the economy passes through the long transition with a comparatively low price for R\&D and a comparatively high price for human capital and a stable growth path for total differentiated capital. The steady state is achieved with an output growth rate of 3.05\% and the corresponding welfare effect is the highest despite the long adjustment of consumption during the transition period.

Though in a particularly different framework, Grossman (2007) also emphasizes strong reallocation effects for human capital under different subsidy schemes. In an economic environment where R\&D production is based on skills, he shows that higher R\&D subsidies imply higher demand for skilled labor, more people choose to acquire skills and for a given government budget the quality of skilled labor decreases. Grossman, emphasizing such effect of R\&D subsidies concludes that a public education program aiming at science and engineering skills enhancement is associated with higher long-run growth. In a recent paper, Gomez and Sequeira (2013), present a model similar to ours with R\&D, human capital and physical capital calibrated to US economy and bring forward the question of R\&D subsidization policy. In a model with comprehensive R\&D externalities, their analyses imply that R\&D subsidies are most welfare increasing when the main target is to keep the intertemporal budget balance. They also find that the most long-run growth improving policy is to increase subsidy to education. Our results are comparable to this set of references with its emphasis on the tradeoff effects in the allocation of resources and the rich environment offered by the transition dynamics. As we have observed, the transition paths followed fluctuations and abrupt swings in response to the policy interventions modeled, and this calls for further efforts to devise an optimal sequencing and implementation. Initial steps of such an endeavor have been studied by Grossman et al. (2013) implying strong policy effects.

\section{Conclusion}

In this paper we investigated alternative public policy intervention schemes within the context of an applied endogenous growth model with human and knowledge capital accumulation. Utilizing data from the Canadian economy, we first studied subsidization of the build-up of human capital through education against subsidization of the R\&D activities. Such instruments are basically designed to enhance growth via stimulating processes of factor accumulation along with internalization of external economies associated with the "public good" characteristics of knowledge and technological innovation. A subsidy to education affects the household's response to allocate human capital among different sectors/activities. A subsidy to R\&D, on the other hand, drives the primary resources toward the R\&D sector, by offering a higher (subsidized) return.

Our simulation results reveal long-lasting effects and nonconventional trade-offs both across instruments and also across time periods. A subsidy to education, attracting human capital away from marketed activities, produces an initial negative effect on the productive (final good) sectors. Although the growth rate (and welfare) recovers in the long-run steady state, the GDP and consumption paths under the education subsidy are much less favorable during transition, adversely affecting the current generations. On the other hand, the R\&D subsidy scheme advances the R\&D sector by pulling primary resources away from the alternatives. The subsidy to the cost of R\&D production stimulates an upward shift in the production of differentiated capital as well as the final goods sector in the economy. Thus, the R\&D subsidy creates a more direct effect in terms of the allocation of resources to the marketed activities, leading to higher average growth rate during transition, toward the new steady state. Higher level of output enables higher level of consumption, both during transition and at the new steady-state, relative to the benchmark.

We also find that under the education subsidy scenario the welfare index changes sign during the course of adjustment, as the negative impact of considerably lower production, income and consumption throughout the transition becomes more pronounced as the economy moves to the new steady state. Our results indicate the importance of taking into account the transition dynamics: a policy toward subsidizing the (market-oriented) R\&D definitely has important positive effects during the (long) transition period, perhaps balancing for the lower long-run equilibrium growth rate. Such trade-offs are also noticeable in the design of the optimal subsidy scheme, which calls for a combination of education and R\&D subsidies. Here, too, the positive dynamics of the combined, welfare-enhancing subsidy sets in after a long transition period.

Within the Canadian context, we believe that our results could substantially contribute to the ongoing debate over the "Canadian innovation deficit", which has been the main motivation of this study. Based on the re-allocation effects triggered by the public subsidization policies on higher education versus the industry/business R\&D, our results corroborate with the recent assessments that the Canadian economy may be falling short of its potential in technological innovation and R\&D production. Compared to other developed countries, Canada has lower and decreasing total R\&D expenditure and lower industry/business finance and performance in R\&D production, and stronger presence of higher education in R\&D performance. Coupled with relatively low human capital employment in industry/business R\&D and relatively high human capital employment in higher education, within the context of our model, an implication would be lower (than potential) growth derived from strong re-allocation effects. Our results suggest that Canadian policy makers could aim toward a policy mix with a strong emphasis on subsidy to (direct) R\&D with a moderated emphasis on the subsidies to higher education to be able to have an optimal division of the human capital among different sectors of the economy.

Lastly, from the modeling viewpoint, one issue is the extension of possible trade offs across leisure and work. In the context of this model this would entail a trade off between educated personnel (human capital) and leisure with the wage rate in human capital formation serving as the opportunity cost. It ought to be recalled that our treatment of human capital here is quite narrow, covering only the skilled technicians and educated labor - "human capitalists to produce more human capital". In this narrow sense, we also find that extending possibilities of leisure to this factor would add little realism at the cost of increased complexity of the model, especially the characterization of the steady state paths. However in more indepth and realistic depictions of the labor markets, such an extension would definitely prove worthwhile to pursue.

\section{Appendix A}

\section{A.1. The data and the calibration strategy}

The data related to the initial period's equilibrium are drawn primarily from the HRSD-Canada data set for the year 2003. As the HRSDC data are originally in the form of annual flow values and primarily compiled for the purpose of static general equilibrium analyses, they need to be 
further augmented by information associated with the Canadian growth path, namely, physical and human capital stock, technological knowledge stock, R\&D expenditures, growth rate(s), interest rate, and the discount rate in the intertemporal utility function.

The intertemporal elasticity of substitution, $1 / \sigma$, in the household utility function is chosen in the range estimated by Hall (1988). The rate of time preference, $\rho$, is taken from Lucas (1988). The average long run growth rate of the economy, $g^{Y}$, taken to be $3.0 \%$, matches the data on the long-run growth path of the Canadian economy. The initial steady state growth rate for human capital, hence for R\&D thereby, is solved in accordance with the steady state rate of growth of the economy and the shares of human and physical capital in the value added of the final output, $\alpha_{H}$ and $\alpha_{k}$. The initial interest rate, $r_{0}$ then has to be calculated in a way consistent with the choices of $\sigma, \rho$, and $g^{A}(0) .{ }^{15}$ We further assume that the depreciation rate of capital varieties is zero.

Detailed data on Canadian Labor Force of the Statistics Canada, together with the data on total R\&D personnel ${ }^{16}$ is compiled to adjust the original HRSDC data for different labor input categories. Accordingly, R\&D personnel in Higher Education and Government sectors with MS and $\mathrm{PhD}$ degrees in Science and Engineering and Social Science together with the MS and $\mathrm{PhD}$ students in Science and Engineering are assumed to form the basis for the share of human capital in education, $u^{H}$ (17.6\%). The rest of the R\&D personnel in Industry/Business and Government are considered to be at the basis for the estimation of the share of human capital in R\&D production, $u^{A}(29.2 \%)$. The rest of the (employed) Science and Engineering and Social Science graduates with MS degrees and higher are assumed to be employed in the final goods sector, $u^{Y}$ (53.2\%). Given the total employment figure for the Canadian economy for 2003, we assume that the rest of the labor force is employed under the category of plain labor, $L$ in the model. ${ }^{17}$

Data on total returns to capital as a factor of production in the benchmark are provided by the HRSDC database. We distinguish the returns to the differentiated capital from the returns to labor resource based on these data. This task is accomplished under the calibration restrictions imposed by the model. For the purpose of calibration, we normalize the ratio of (index of) initial stock of human capital to the (index of) initial stock of $R \& D, H / A$ to 1 .

To ensure the existence of a balanced growth path, we calibrate $\alpha_{k}$, $\alpha_{H}$ price of R\&D, $P^{A}$ and the growth rate of R\&D, $g^{A}(0)=\Delta A_{0} / A_{0}$ simultaneously, depending on Eqs. (26), (27) and (28):

Under the steady state we know that $r_{S S}=g^{P A}+\frac{\Pi_{S S}}{P^{A}}$. Now, recall the GDP identity from Eq. (26):

$P^{Y} Y+P^{A} \Delta A=w^{L} L^{Y}+w^{H}\left(H^{Y}+H^{A}\right)+\frac{\Pi}{\left(1-\alpha_{k}\right)}$.

Using the the no-arbitrage equation we have $\left(1+g^{P A}(t)\right)=\frac{1+r_{t+1}}{1+\frac{I_{t+1}}{P A_{t+1}}}$. Thus, under the steady state equilibrium the national income identity satisfies,

$G D P=w^{L} L^{Y}+w^{H}\left(H^{Y}+H^{A}\right)+\frac{P^{A}}{\left(1-\alpha_{k}\right)}\left(\frac{1+r}{1+g^{P A}}-1\right)$

\footnotetext{
${ }^{15}$ As in static applied GE models, where calibration is based on the assumption that data reflect an economy in equilibrium, we assume that the benchmark data depict an initial steady state growth path. This steady-state assumption for the benchmark data is widely used in applied intertemporal general equilibrium models. For example, Goulder and Summers (1989), Mercenier and Yeldan (1997), and Diao et al (1999).

16 Science Statistics, May 2008.

17 Such an assumption, of course, classifies for instance, BA graduates under plain labor category, $L$ in the model. Therefore, the share of plain labor in the final good value added, $\alpha_{L}$ is estimated to be around $30.0 \%$, a value higher than what is usually set for the Canadian economy (Sturgill, 2009).
}

or equivalently,

$$
\left(1-\alpha_{k}\right)\left[G D P-w^{L} L^{Y}-w^{H}\left(H^{Y}+H^{A}\right)\right]=P^{A}\left(\frac{1+r}{1+g^{P A}}-1\right) .
$$

Using Eq. (26) and (29) together,

$$
\left(1-\alpha_{k}\right) \alpha_{k}\left[G D P-P^{A} \Delta A\right]=P^{A}\left(\frac{1+r}{1+g^{P A}}-1\right) .
$$

Using the fact that $g^{P A}$ and $g^{A}$ are related via Eq. (28) in discrete time as $\left(1+g^{P A}\right)=\left(1+g^{A}\right)^{\frac{\alpha_{H}}{1-\alpha_{k}}}$, and recalling that we have $\Delta A_{0} / A_{0}=g_{A}$, this information will allow us to utilize the following relationship for calibrating $P_{A}$ and $\alpha_{k}$ :

$$
\left(1-\alpha_{k}\right) \alpha_{k}\left[G D P-g^{A} P^{A}\right]=P^{A}\left(\frac{1+r}{1+g^{P A}}-1\right) .
$$

The second simultaneous relationship between $P_{A}$ and $\alpha_{k}$ is obtained from the savings - investment equilibrium condition. Using this condition together with Eq. (14) and making note of the fact that $\triangle A / A=g_{A}$, we have

$S=r \eta g^{A} k+r \eta \Delta k+P^{A} g^{A}$

Since, from the optimal pricing rule of the monopolist (Eq. (10)) $r=$ $\frac{\alpha_{k} p_{k}}{\eta}$, the saving - investment equilibrium can be re-written as

$S=\frac{\alpha_{k}\left(g^{A}+g^{P A}\right)}{r\left(1-\alpha_{k}\right)} P^{A}\left(\frac{1+r}{1+g^{P A}}-1\right)+P^{A} g^{A}$.

Table A-1 presents the initial levels of selected variables and parameters obtained from sources other than the main data base or from this calibration process.

We read the values of $S$, wages paid to human capital in the production of the final good, and the value added of $Y$ from data. For, calibration, we set the initial values of $u^{A}, u^{H}$, and $u^{Y}$ in accordance with the data. Using the F.O.C. in the R\&D production, with $w^{H}$ given, we have $\varphi=w^{H} / P_{A}$. Eqs. (5) and (19) together with the information that at the steady state, $g^{A}=g^{H}$, help one to solve for $\xi$, $\gamma$ and $\epsilon$.

Table A-1

Pre-assumed and calibrated values of structural parameters.

\begin{tabular}{ll}
\hline Share of human capital in final good value added, $\alpha_{H}$ & 0.232 \\
Share of plain labor in final good value added, $\alpha_{L}$ & 0.300 \\
Share of rental value of differentiated capital in final good value added, $\alpha_{K}$ & 0.468 \\
R\&D Production productivity parameter, $\varphi$ & 0.0695 \\
Productivity of schooling in human capital formation, $\xi$ & 0.0296 \\
Productivity of learning via knowledge and varieties, $\gamma$ & 0.0157 \\
Share of past human capital in human capital formation, $\epsilon$ & 0.6956 \\
Value of input output coefficient to produce unit capital variety, $\eta$ & 9.3619 \\
Share of human capital allocated to final good production, $\frac{H_{Y}}{H}\left(u^{Y}\right)$ & 0.5317 \\
Share of human capital allocated to R\&D production, $\frac{H_{A}}{H}\left(u^{A}\right)$ & 0.2922 \\
Share of human capital allocated to human capital formation, $\frac{H_{H}}{H}\left(u^{H}\right)$ & 0.1761 \\
Value of R\&D sector as a ratio to GDP, $\frac{P_{A} \Delta A}{G D P}$ & 0.109 \\
Ratio of aggregate savings to GDP, $\frac{S A V P}{G D P}$ & 0.229 \\
Share of oligopolistic profits in GDP, $\frac{\Pi}{G D P}$ & 0.214 \\
Inverse of intertemporal elasticity of substitution for the consumer, $\sigma$ & 1.0001 \\
Subjective discount rate, $\rho$ & 0.023 \\
Income tax rate, $t_{y}$ & 0.092 \\
Sales tax rate on consumption good, $t_{c}$ & 0.046 \\
Armingtonian elasticity of substitution between $M$ and $D C, \varepsilon_{C C}$ & 3.000 \\
CET elasticity of transformation between $E$ and $D C, \varepsilon_{C E T}$ & 3.000
\end{tabular}




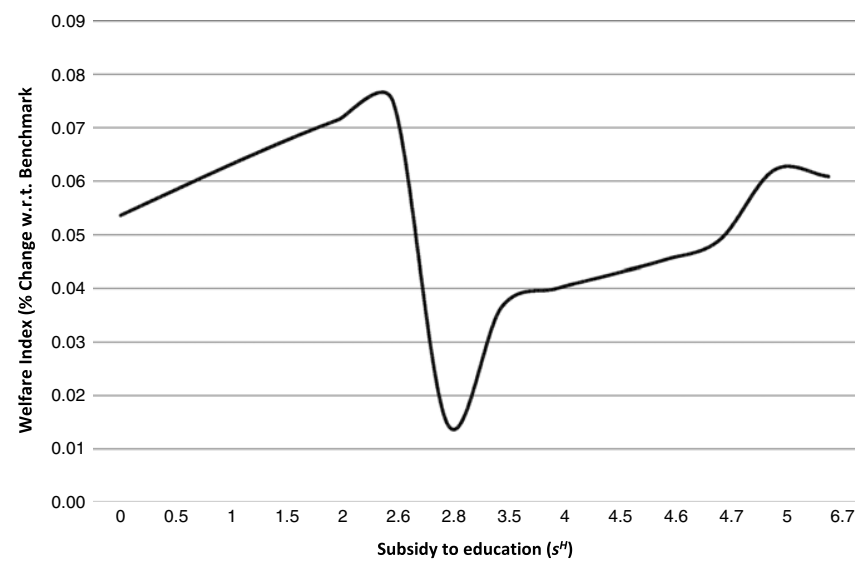

Fig. A-1. Welfare maximization under alternative subsidy combinations (w.r.t. base run).

Finally, using discrete time, condition for equilibrium growth of consumption is

$\left(\frac{1+r_{S S}}{1+\rho}\right)^{1 / \theta}=1+g^{c}$

Thus growth in final good becomes $g^{Y}=g^{c}$. The rest of the system is calibrated using standard methods of applied general equilibrium.

\section{A.2. Searching for optimal subsidy structure}

Fig. A-1 implies that, under the budgetary restriction for the total amount of subsidies, the welfare of current and future generations increases with a movement from a pure R\&D subsidy policy to a combination of R\&D subsidy $\left(S^{R}=3.7 \%\right)$ and education subsidy $\left(S^{H}=2.6 \%\right)$. Yet, such an effect does not follow a steady path: the welfare effect is the lowest when the education and the R\&D subsidy rates change to be very close to each other $\left(S^{R}=2.7 \%\right.$ and $\left.s^{H}=2.8 \%\right) .{ }^{18}$ Under such a mix of policy tools, the growth and welfare augmenting effects of both subsidies tend to offset each other. The figure also demonstrates the anatomy of the slightly higher welfare index associated with the pure education subsidy policy compared to the pure R\&D subsidy policy.

\section{References}

Agénor, P.R., 2012. Public Capital, Growth and Welfare: Analytical Foundations for Public Policy. Princeton University Press, Princeton and Oxford.

Aghion, P., Howitt, P., 1997. Endogenous Growth Theory. MIT Press, Cambridge.

Annabi, N., Harvey, S., Lan, Y., 2011. Public expenditures on education, human capital and growth in Canada: an OLG model analysis. J. Policy Model 33, 852-865.

Arnold, L., 1998. Growth, welfare and trade in an integrated model of human-capital accumulation and research. J. Macroecon. 20 (1), 81-105.

Arrow, K.J., 1962. The economic implications of learning by doing. Rev. Econ. Stud. 29, $155-173$.

Banerjee, R., Robson, W., 2007. Give Canadian workers the tools to do the job! Why Canada needs more robust capital investment. e-brief no. 44. C.D. Howe Institute, Toronto.

Bye, B., Faehn, T., Heggedal, T., 2009. Welfare and growth impacts of innovation policies in a small, open economy; an applied general equilibrium analysis. Econ. Model. 26, $1075-1088$.
Cook, E. 2008 Beyond Curiosity: Achieving prosperity with a balanced innovation system. Mimeo.

Dalgaard, C.J., Kreiner, C.T., 2001. Is declining productivity inevitable. J. Econ. Growth 6, 187-203.

Diao, X., Roe, T., Yeldan, E., 1999. Strategic policies and growth: an applied model of R\&Ddriven endogenous growth. J. Dev. Econ. 60, 343-380.

Eicher, T.S., 1996. Interaction between endogenous human capital and technological change. Rev. Econ. Stud. 63, 127-144.

Frantzen, D., 2000. R\&D, human capital and international technology spillovers: a crosscountry analysis. Scand. J. Econ. 102 (1), 5775

Funke, M., Strulik, H., 2000. On endogenous growth with physical capital, human capital and product variety. Eur. Econ. Rev. 44, 491-515.

Galor, O., 2005. From Stagnation to Growth: Unified Growth Theory, in Handbook of Economic Growth. North-Holland, Amsterdam.

Ghosh, M., 2007. R\&D policies and endogenous growth: a dynamic general equilibrium analysis of the case for Canada. Rev. Dev. Econ. 11 (1), 187-203.

Gomez, M.A., Sequeira, T.N., 2013. Optimal R\&D subsidies in a model with physical capital, human capital and varieties. Econ. Model. 30, 217-224.

Gomez, M.A., Sequeira, T.N., 2014. Should the US increase subsidies to R\&D? Lessons from an endogenous growth theory. Oxf. Econ. Pap. 66 (1), 254-282.

Goulder, L.H., Summers, L.H., 1989. Tax policy, asset prices, and growth: a general equilibrium analysis. J. Public Econ. 38 (3), 265-296.

Grossman, V., 2007. How to promote R\&D-based growth? Public education expenditure on scientists and engineers versus R\&D subsidies. J. Macroecon. 29, 891-911.

Grossman, G.M., Helpman, E., 1991. Innovation and Growth in the Global Economy. The MIT Press, Cambridge.

Grossman, G.M., Helpman, E., 1994. Endogenous innovation in the theory of growth. J. Econ. Perspect. 8, 23-41.

Grossman, V., Steger, T., Trimborn, T., 2013. Dynamically optimal R\&D subsidization. J. Econ. Dyn. Control. 37, 516-534.

Hagedorn, M., Kaul A. and Reinthaler V. 2003. Optimal taxation in R\&D-based growth models. Mimeo.

Hall, R.E., 1988. Intertemporal substitution in consumption. J. Polit. Econ. 96 (2), 339-357.

Jones, L.E., Manuelli, R.E., 1990. A convex model of equilibrium growth: theory and policy implications. J. Polit. Econ. 98 (5), 1008-1038.

Keller, W., 1996. Absorptive capacity: on the creation and acquisition of technology in development. J. Dev. Econ. 49 (1), 199-227.

King, R.G., Rebelo, S.T., 1993. Transitional dynamics and economic growth in the neoclassical model. Am. Econ. Rev. 83 (4), 908-931.

Lucas, R.E., 1988. On the mechanics of economic development. J. Monet. Econ. 22, 3-44.

Mattalia, C., 2012. Human capital accumulation in R\&D-based growth models. Econ. Model. 29, 601-609.

McFetridge, D.G., 2008. Innovation and the productivity problem: any solutions? IIRP Choices 14 (3), 2-36.

Mercenier, J., Yeldan, E., 1997. On Turkey's trade policy: is a customs union with Europe enough? Eur. Econ. Rev. 41 (3-5), 871-880.

Munroe-Blum, H., MacKinnon, P., 2009. Canada's innovation deficit. Policy Optionspp. 8-10 (vol. June 2009)

OECD, 2003. The Sources of Economic Growth in OECD Countries (Paris).

Rebelo, S.T., 1991. Long-run policy analysis and long-run growth. J. Polit. Econ. 99 (3), 500-521.

Riberio-Thompson, M.J., 2000. A nonscale growth model with R\&D and human capital accumulation. Working Paper. University of Warwick, Department of Economics.

Romer, P.M., 1990. Endogenous technological change. J. Polit. Econ. 98 (5), S71-S102.

Russo, B., 2004. A cost-benefit analysis of R\&D tax incentives. Can. J. Econ. 37, 313-335.

Sequeira, T.N., 2008. On the effects of human capital and R\&D policies in an endogenous growth model. Econ. Model. 25, 968-982.

Sequeira, T.N., 2011. R\&D spillovers in an endogenous growth model with physical capital, human capital and varieties. Macroecon. Dyn. 15, 223-239.

Sharpe, A., 2007. Lessons for Canada from international productivity experience. Int. Product. Monit. 20 (Spring), 20-37.

Stewart, J., 2011. Canada's innovation puzzle: is our national conversation missing a piece? Policy Optionspp. 42-46 (Vol. Sept. 2011)

Sturgill, B., 2009. Cross-country variation in factor shares and its implications for development accounting. Department of Economics, Appalachian State University Working Paper, No: 09-07.

Therrien, P., Mohnen, P., 2003. How innovative are Canadian firms compared to some European firms? A comparative look at innovation surveys. Technovation 23 (4), 359-369.

Zeng, J., 2003. Reexamining the interaction between innovation and capital accumulation. J. Macroecon. 25 (4), 541-560.

\footnotetext{
18 Recently, in a model with physical capital, human capital and R\&D production, Gomez and Sequeira (2013) also show that the path for the optimal R\&D subsidy can be nonmonotonic.
} 